\title{
Organic Farming: A Path to Healthy Food and Environment
}

\author{
P. P. Patel ${ }^{1^{*}}$ and D. D. Champaneri ${ }^{2}$ \\ ${ }^{1}$ ASPEE College of Horticulture and Forestry, Navsari Agricultural University, Navsari, \\ Gujarat - 396450, India \\ ${ }^{2}$ Department of Vegetable Science, ASPEE College of Horticulture and Forestry, Navsari \\ Agricultural University, Navsari, Gujarat - 396450, India \\ *Corresponding author
}

\begin{tabular}{|c|}
\hline $\begin{array}{l}\text { K e y w o r d s } \\
\text { organic, } \\
\text { environment, } \\
\text { horticulture, } \\
\text { agriculture, soil } \\
\text { health, economics }\end{array}$ \\
\hline Article Info \\
\hline $\begin{array}{l}\text { Accepted: } \\
\text { 05 February } 2020 \\
\text { Available Online: } \\
10 \text { March } 2020\end{array}$ \\
\hline
\end{tabular}

A B S T R A C T

Conventional farming methods have significantly increased yields but in recent times due to the increased awareness of people about health, there has been increasing demand of organically grown foods. Organic farming helps in maintaining soil health and thereby produce healthy and quality food materials. This concern has prompted an expanding enthusiasm for organic farming methods since they may diminish a portion of the negative impacts of conventional farming on the earth. Different organic farming methods have been used for many years to make agriculture and horticulture practical while preserving soil, water, energy, and organic assets. The future of agribusiness can be made increasingly economical and naturally solid by embracing some traditional organic farming methods and technologies.

\section{Introduction}

In the recent times, various issues related to health of human beings are debated which are directly or indirectly linked to the heavy use of synthetic agrochemicals in crop production and their residual effect (Pimentel et al., 2005). This has led to the increased awareness in public about their health and organic farming is again back into the practices which was practiced before the invention of agrochemicals and huge numbers of farmers are moving towards the organic farming of different crops. Organic farming can be defined as cultivation of crops without the use of synthetic chemicals like agrochemicals and use of compost manure, neem based products, green compost and practice crop rotation to grow the crops.

It is an integrated farming system that focuses on sustainability, enhancement of soil flora and fauna and thereby maintaining soil fertility. Organic farming prohibits use of synthetic pesticides, synthetic fertilizers, antibiotics, growth hormones and genetically modified organisms. It aims on providing healthy food. To overcome the losses 
confronted by conventional farming methods, organic farming concept is now greatly emphasized. Integrated pest management and nutrient management by using more of organic products can help in reducing the use of synthetic chemicals and can make environment healthy and sound. Government of some countries like Sweden, Canada, etc. have demonstrated that use of pesticides can be greatly reduced without loss of yield and quality (BANR/NRC 2003).

Organic farming methods can eliminate use of synthetic agrochemicals and reduce other inputs to improve the environment and farm business. The goal of organic farming is to conserve the ecological processes, improve nutrients intake and save water resources. With ongoing concerns about nature and the synthetic chemical substances utilized in food production, and with the developing accessibility of guaranteed certified organic food production, the viewpoint for proceeding with development of organic food production is brilliant (Dimitri and Greene 2002).
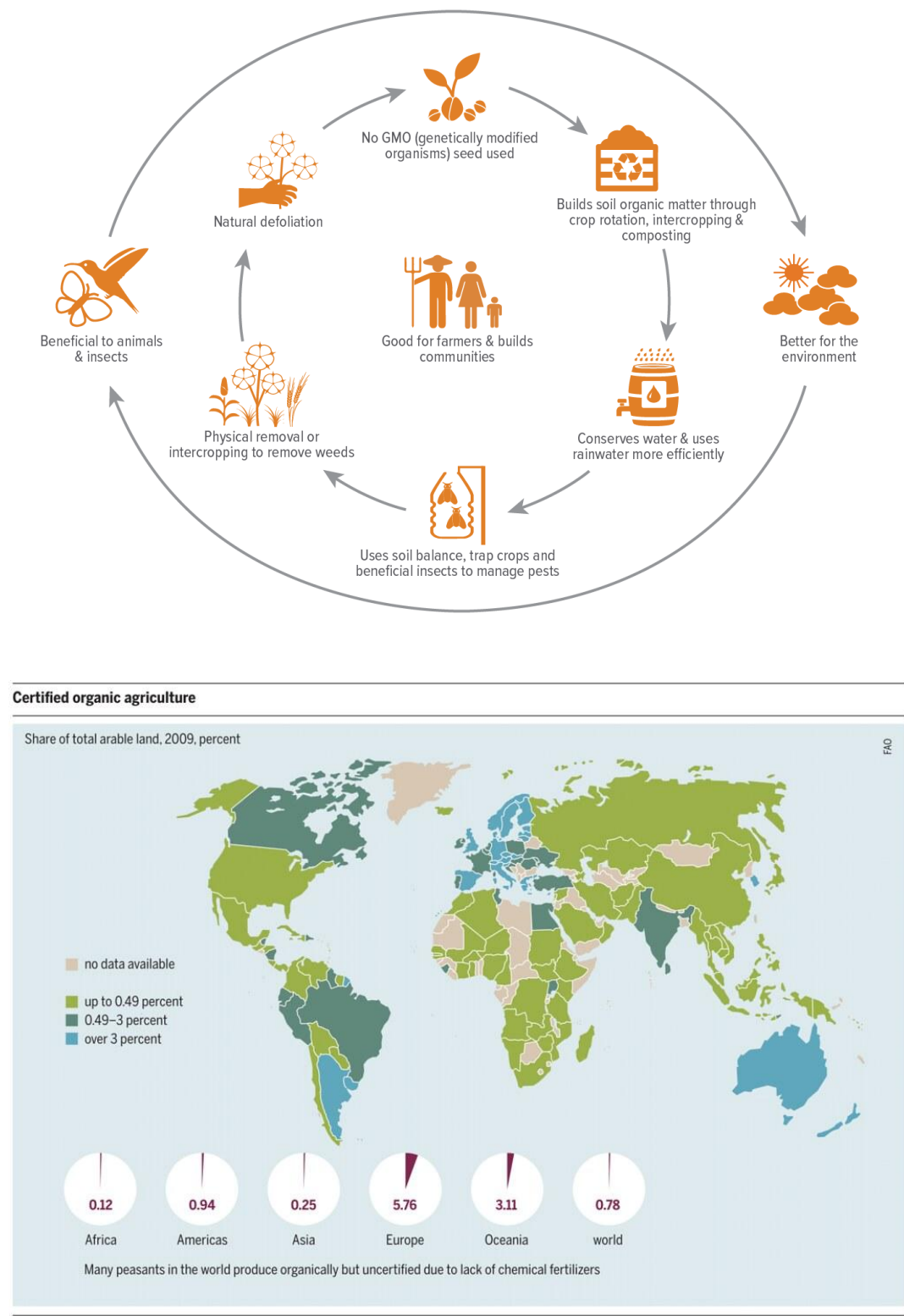
This paper focuses on the various findings of research to investigate soil health, environment and economics of organic farming on different types of crops. Various advantages and the need of organic farming in present times has been analyzed and presented.

\section{Soil Health Aspects}

Growing research and evidences links management of farms and land, soil health and plant health yet connections among soil health, food crop dietary and nutritional quality, and human health with wellbeing are less understood. Various examinations are done so as to reveal insight into these connections about organic farming and soil health. Organic farming systems use carbonbased changes, differing crop revolutions, and spread crops to build soil fertility.

These practices increase biologically accessible soil organic matter and helpful soil microorganisms and invertebrate activities, improve soil physical properties, diminish disease potential and increase plant health and leading to good growth and development of plants. Ongoing researches proposes that organically grown products contain more significant levels of health promoting phytochemicals, potentially connected to more prominent plant stress, rhizosphere microbial networks, and additionally lower accessible nitrogen. Yet, the overlap in different management practices among different farming systems makes broad generalizations troublesome. Besides, ecological and crop species or potentially cultivar interactions may apply more grounded impacts than the management.

Complex connections exist between various segments of the organic farm and the quantity and quality of the end products rely upon the working of the entire framework and systems.
All things considered, it is extremely hard to separate soil fertility from production and ecological parts of the system. Crop rotation is the focal apparatus that coordinates the maintenance and improvement of soil fertility with various aspects of crop and livestock production in natural systems. Supplemental nutrients supply to crops relies upon the use of legumes and vegetables to add nitrogen to the soil in acceptable forms.

Organic manures and farm waste are deliberately figured out that how to reuse supplements around the farm. The management of soil organic matter, basically using short term leys, guarantees great soil structure and biological action, significant for supplement supply, health and profitability of the both- harvested crops and domesticated animals. Carefully planned diverse rotations helps in lessening the frequency of pests and diseases and take into account cultural methods and various techniques for weed control. Because of the intricate interactions between various components of a system, fertility management in organic farming depends on a long term coordinated approach.

Organic farming heavily relies upon green manuring and increasing the levels of organic matter in the soil. The use of organic materials has shown positive effects on the various properties of the soil. Increasing the levels of organic matter in the organic farming methods can cause fluctuations in the ion concentrations of soil and soil $\mathrm{pH}$. Supplements high in organic matter when incorporated heavily in soil leads to increase in the faunal population which are beneficial to maintain the soil fertility.

Various researches shows that the farms on which organic farming has been practiced over years have higher levels of organic matter, total nitrogen content, has high cation exchange capacity. Also this soils have high 
extractable potassium, water content, $\mathrm{pH}$, polysaccharide content, enzyme levels and good amount of microbial biomass. Organically farmed based soil also has good physical properties like more granular structure, less hard and more friable. Research proved that organic farmed based soils also shows lesser amount of soil erosion due to good soil structure which can be maintained by different crop rotations. Organic farms include green manure crop in its rotation and had different tillage methods which provides benefits against soil erosion. This indicates that organic farming over long period has greater benefits in maintaining soil tilth and other soil properties.

Lower amount of organic matter in the soil leads to poor soil structure and it inhibit crop rooting. Vegetable crops are mostly shallow rooted crops and this affects the rooting of the plants and thereby affecting the growth and development of the plant. Organic matter in the soil can help in even distribution of nutrients and micronutrients can be easily available. Organic materials in the soil binds the particles and make good structure of soil which helps in better activity of root system and also increase the uptake of nutrients from the soil as they can be easily available. Organic matter provides better aeration in the soil due to aggregate formation.

Nutrient cycling efficiencies can be greatly balanced by using organic matter which can be observed in organic farming. Organic matter in the soil can help in storing of water and thereby reducing the ill effects of drought on plants.

Organic farming also helps to increase the beneficial microbes in the soil and augment them. Fungus, nematodes and other organism are present in abundant quantity in organic farming based soils. Parasitic fungus are available in high amount which controls the level of harmful fungus which hampers the plant growth and productivity. But contrary to this sometimes high level of harmful organisms can also be observed. Mycorrhizal fungi are very useful in organic farming as they acts as natural fertilizers and helps in increasing plant yield. It also contributes to increase crop productivity and enhancing ecosystem sustainaibility.

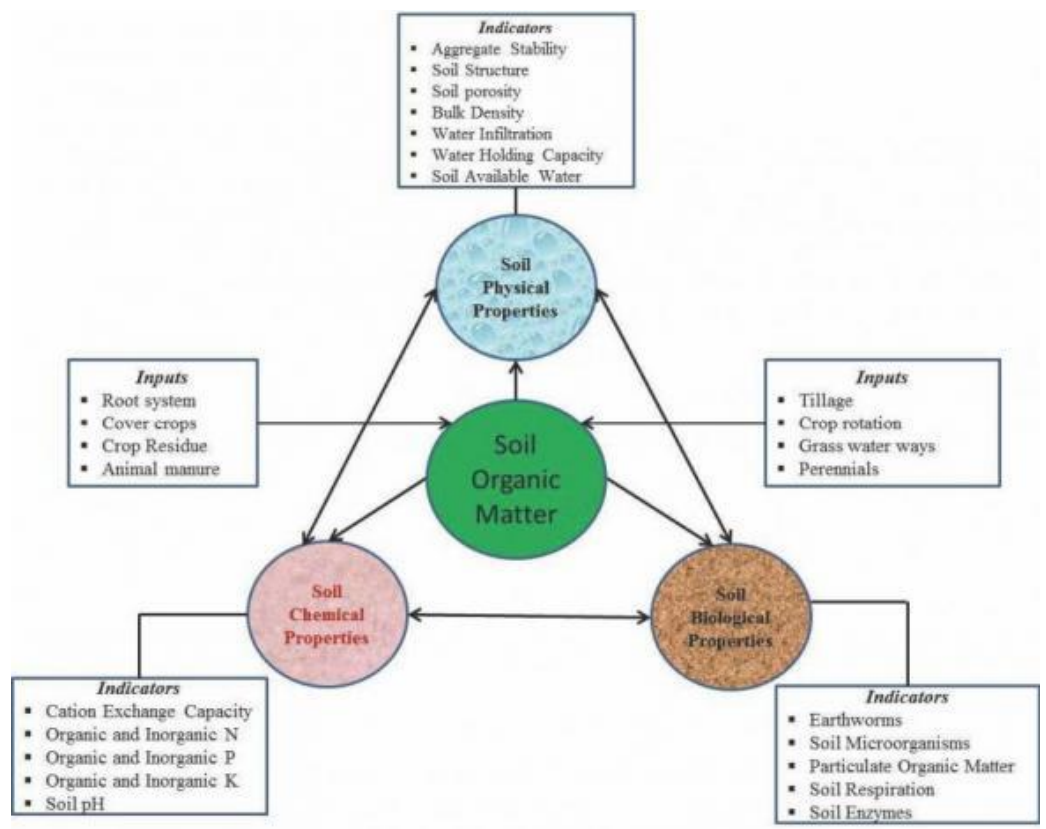




\section{Environment Aspects}

Organic farming methods have been advanced as, inter alia, diminishing the environmental effects of agriculture. Organic farming practices commonly have positive and beneficial on the environment per unit of zone, yet not really per product unit. Organic farms in general have higher soil organic substance and lower nutrient losses (nitrogen draining, nitrous oxide emissions and alkali emissions) per unit of field area. However, alkali emissions, nitrogen leaching and nitrous oxide emission per item unit are higher from natural and organic farming.

Organic farming had lower energy requirements, yet higher land use, eutrophication potential and fermentation potential per product unit. Impacts that are found to vary altogether between the systems are soil organic matter content, nitrogen leaching, nitrous oxide emissions per unit of field area, energy use and land use. A large portion of the examinations that thought about biodiversity in organic cultivating exhibited lower ecological effects. In organic farming, the principle challenges are to improve the nutrient management and increase yields. Cropping patterns can influence the impact on environment of farming systems. Mono cropping which is essential in organic farming certification is factor impacting the environment of the organic farming.

The arrangement of food production system causes environmental effects that range from local through to worldwide in scale. Organic farming, used here to mean farming practices with a more prominent emphasis on long term sustainability, is one general way to deal with reduce these effects. While organic farming might be contended to be better than conventional cultivating based on local impacts, it is indeed not clear how organic farming performs comparative with conventional farming regarding more extensive, worldwide effects. Direct energy use, energy related emissions, and ozone depleting greenhouse gases are higher for the organic farming test. Direct water use and business are lower for the organic farms. Overall the emissions and other factors impacting greenhouse effect are not too much high in the organic farming systems.

Various comprehensive assessment tools are required for describing overall environmental impacts of different agriculture systems for developing highly sustainable systems for more production and less environmental effects. Presently LCA (Life Cycle Assessment) is being greatly utilized to compare the environmental sustainability of different farming methods and their products. When LCA studies are performed for organic farming methods it shows wide variation in the results. More variation is observed in resource efficiency of products from this different methods of farming. The studies shows that impacts on environment per area of farmed land are usually less in organic farming but when related to quantity produced environmental effects are often greater.

Organic farming uses low agricultural inputs and it results in low energy demand. Organic farming can help in energy savings and carbon sequestration when practiced on huge scale. Also it provides number of important environmental and social services like improving and maintaining the soil quality, increasing carbon sink, reducing the water usage, preserving biodiversity, reducing the use of harmful chemicals which guarantees safe food to people.

Insect- pests and pathogens are the major problems in growing food organically by various organic farming methods. It can be controlled by employing various crop rotation 
techniques. Some pests can be controlled by various parasitoids. Controlling of pests by parasitoids in organic farming of tomato has shown good results. Augmentation of various biological fauna can help in destruction of harmful pests and disease causing organisms.

Use of agrochemicals which are harmful to human health can be lowered by use of parasitoids, entomopathogens, etc. In organic farming systems oils and natural chemicals are largely used which indirectly provides good environmental effect. Neem based products are widely used for controlling various types of pests and diseases. Due to this environmental impacts can be lessened as lower usage of chemicals by which soil and human health can be benefited.

Organic farming plays another role in maintaining and harboring various floral and faunal biodiversity. When organic farming is practiced it maintains the species in an environment. GMO ( Genetically modified organisms ) are also not permitted in organic farming systems as they disturb the habitat of natural flora and fauna. The restricted use of pesticides in the organic farming approach results in higher biodiversity of flora and fauna. With the increased organisms biodiversity in the soil it can lead to increased activity in soil which helps in soil health management.

Various types of fauna helps in pollination and increase the crop productivity. Researches shows that when organic farming is practiced in a proper and sustained way it can avoid losses of species and increase the landscape view of the surroundings. Contamination of water with chemicals leads to deterioration of environment and also effects the human health. Contamination of groundwater with various chemicals can also be avoided in organic farming systems.

Research showed that the population of bumble bees are affected with context to the landscape of the farms and its practices. Higher homogeneity is observed in the landscape of the organic farms with species richness and its abundance which attracts the bumble bees. Another factor affecting the attraction of bees to organic farming landscapes is number of different flowers and abundance on the site.

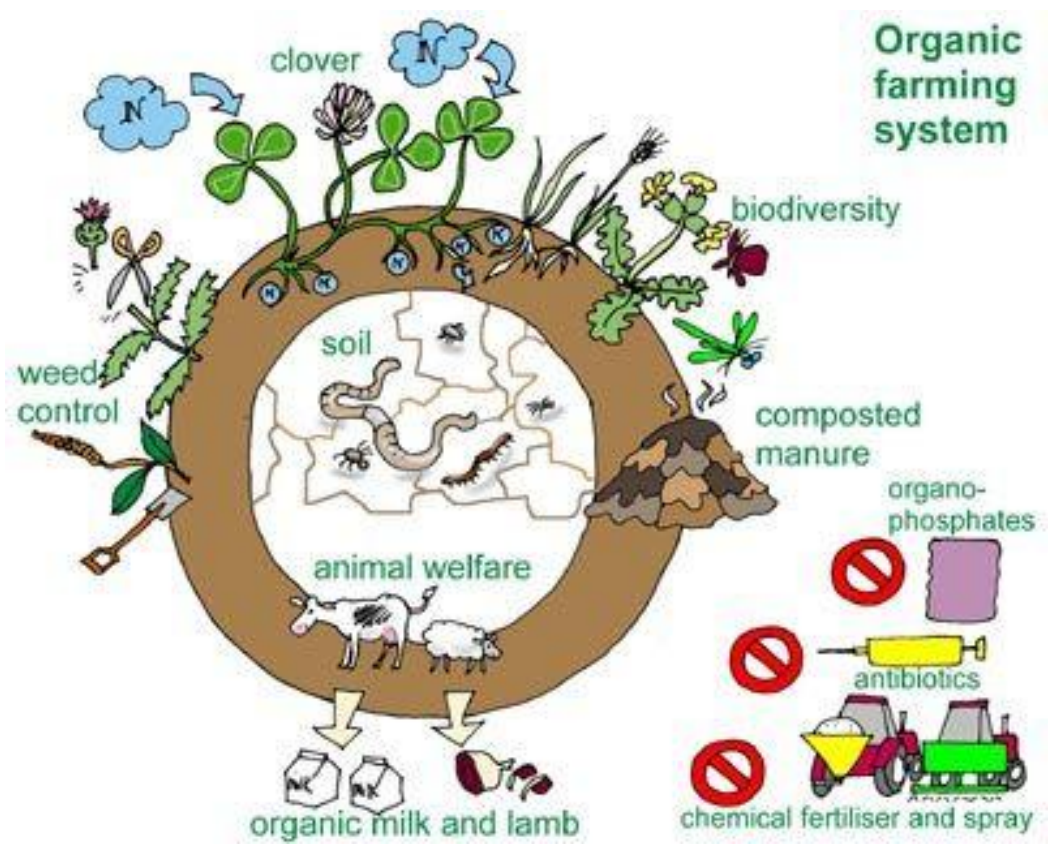




\section{Economics Aspects}

Organic products are in huge demand nowadays due to increased awareness about health in public. Organic products comes at higher prices due to increased cost of cultivation in terms of money for producing healthy foods. Planting materials, organic manures, plant protection and other things increase the cost of cultivation. Organic technologies when used for organic farming requires higher labour inputs. Yields can be substantially reduced for major horticultural crops in organic farming which decreases the profit level of farmers. In organic farming, weed competition is one major issue which leads to increase in the cost of cultivation.

Organic farming when seen on long term benefits then surely it is beneficial to the farmers. Organic farming while protecting the environmental also provides healthy food and good returns of capital in long term farming. Organic certification provides farmers huge benefits of selling their products at premium prices. Due to high demand of organic products in market, products are sold easily. Also people buy it at high prices, concerning their health.

Although the input costs in organic farming are more, the net returns are also more in organic farming when practiced on large scale and for long time. Since ages many different organic methods have been used in agriculture which preserves soil, water and air. In future too, indulging in organic farming methods can be sustainable for environment and economical for business. Organic farming has many benefits like maintaining overall soil health, protecting biodiversity and environment, healthy food production and many more. Thus, clearly organic farming is more beneficial in all the aspects like ecological, economical and social aspects.

\section{References}

Arden-Clarke, C., and Hodges, R. D. (1988). The environmental effects of conventional and organic/biological farming systems. II. Soil ecology, soil fertility and nutrient cycles. Biological Agriculture \& Horticulture, 5(3), 223287.

[BANR/NRC] Board on Agriculture and Natural Resources, National Research Council. 2003. Frontiers in Agricultural Research: Food, Health, Environment, and Communities.

Delate, K., Duffy, M., Chase, C., Holste, A., Friedrich, H., \& Wantate, N. (2003). An economic comparison of organic and conventional grain crops in a long-term agro ecological research (LTAR) site in lowa. American Journal of Alternative Agriculture, 18(2), 59-69.

Dimitri C, Greene C. 2002. Organic food industry taps growing American market. Agricultural Outlook (October): 4-7.

Gomiero, T., Paoletti, M. G., \& Pimentel, D. (2008). Energy and environmental issues in organic and conventional agriculture. Critical Reviews in Plant Sciences, 27(4), 239-254.

Gomiero, T., Pimentel, D., \& Paoletti, M. G. (2011). Environmental impact of different agricultural management practices: conventional vs. organic agriculture. Critical reviews in plant sciences, 30(1-2), 95-124.

Hartmann, M., Frey, B., Mayer, J., Mäder, P., \& Widmer, F. (2015). Distinct soil microbial diversity under long-term organic and conventional farming. The ISME journal, 9(5), 1177.

Pimentel, D. (1993). Economics and energetics of organic and conventional farming. Journal of Agricultural and Environmental Ethics, 6(1), 53-60.

Pimentel, D., Hepperly, P., Hanson, J., Seidel, R., \& Douds, D. (2005). Organic and 
conventional farming systems: Environmental and economic issues.

Reeve, J. R., Hoagland, L. A., Villalba, J. J., Carr, P. M., Atucha, A., Cambardella, C., ... \& Delate, K. (2016). Organic farming, soil health, and food quality: considering possible links. In Advances in agronomy (Vol. 137, pp. 319-367). Academic Press.

Reganold, J. P. (1988). Comparison of soil properties as influenced by organic and conventional farming systems. American Journal of Alternative Agriculture, 3(4), 144-155.

Rundlöf, M., Nilsson, H., \& Smith, H. G. (2008). Interacting effects of farming practice and landscape context on bumble bees. Biological Conservation, 141(2), 417-426.
Tuomisto, H. L., Hodge, I. D., Riordan, P., \& Macdonald, D. W. (2012). Does organic farming reduce environmental impacts?-A meta-analysis of European research. Journal of environmental management, 112, 309-320.

Van der Heijden, M., Rinaudo, V., Verbruggen, E., Scherrer, C., Bàrberi, P., \& Giovannetti, M. (2008). The significance of mycorrhizal fungi for crop productivity and ecosystem sustainability in organic farming systems.

Wood, R., Lenzen, M., Dey, C., \& Lundie, S. (2006). A comparative study of some environmental impacts of conventional and organic farming in Australia. Agricultural systems, 89(2-3), 324-348.

\section{How to cite this article:}

Patel. P. P. and Champaneri. D. D. 2020. Organic Farming: A Path to Healthy Food and Environment. Int.J.Curr.Microbiol.App.Sci. 9(03): 637-644. doi: https://doi.org/10.20546/ijcmas.2020.903.076 